\title{
Understanding the Relationships between Environmental and Social Risk Factors and Financial Performance of Global Infrastructure Projects* $^{*}$
}

\author{
Daniil Kiose, Steve Keen \\ Department of Economics, Kingston University, London, UK \\ Email:d.kiose@kingston.ac.uk, steve.keen@kingston.ac.uk
}

How to cite this paper: Kiose, D. and Keen, S. (2017) Understanding the Relationships between Environmental and Social Risk Factors and Financial Performance of Global Infrastructure Projects. iBusiness, 9, 80-100. https://doi.org/10.4236/ib.2017.94007

Received: September 25, 2017

Accepted: December 3, 2017

Published: December 6, 2017

Copyright (c) 2017 by authors and Scientific Research Publishing Inc. This work is licensed under the Creative Commons Attribution International License (CC BY 4.0).

http://creativecommons.org/licenses/by/4.0/

\section{(c) (i) Open Access}

\begin{abstract}
This study analyses the link between environmental and social risk (ESR) factors and the risk-return profile of infrastructure bonds. We provide support for the hypothesis that credit standing of infrastructure bonds is associated with ESR factors. Considering these factors along with bond and issuer specific information we discovered that several environmental and social risk covariates are strongly related to 1) expected risk-return profile of infrastructure bonds; and 2) the balance of risk around the expectation. Thus along with traditional drivers of bond risks (e.g. time to maturity, base interest rate, etc.) we find that also $\mathrm{CO}_{2}$ emission and percentage of independent directors emerge as important predictors. This study benefits from thoroughly developed, justified and validated non-parametric regression model used to derive key insights into the research question. This work makes a methodological contribution by applying non-parametric modelling techniques to study the financial risk of infrastructure projects. Moreover, it provides bond investors as well as policy makers with the guidance on where to focus their attention.
\end{abstract}

\section{Keywords}

Environmental Risk, Social Risk, Infrastructure Bonds, Generalised Additive Models

\section{Introduction}

Environmental and social risk factors are increasingly becoming part of the metrics used by investment professionals to analyse and value the financial loss as-

*This research was funded by WWF Schweiz, Hohlstrasse 110, 8010 Zürich, Switzerland. 
sociated with infrastructure projects they invest in. With increasing regulatory movement towards environmental and social responsibility, the lending financial institutions can be judged for being responsible for the borrower's activities and treated as partakers in civil or criminal liability [1]. These financial institutions may also suffer because of the effect that ESR matters can have on borrower's repayment ability of a loan and its security. Therefore it became apparent that financial institutions due to direct or indirect liability for ESR matters may experience loss of income. Moreover, this loss of income can even double in the event where both direct and indirect liabilities emerge simultaneously [2].

Along with known environmental issues (e.g. waste disposal, carbon emissions, resource depletion, ecosystem change, etc.) social factors (such as worker rights, safety, child labour, human rights, community relations, etc.) play an increasingly important role in public's and government's perception of the listed companies. There are several ESR related transmission channels (suggested by Mark Hoff and Martin [3]) through which infrastructure projects and hence investors can incur a financial loss.

First of all ignoring environmental and social concerns harms the reputation of the project and its investors by reducing project credibility. An increasing number of construction firms have adopted corporate social responsibility business approach aiming to enhance the brand image and improve financial performance [4]. In particular, they applied ISO 14000 series environmental management systems on a voluntary basis, providing organisations with a useful tool to manage the impact of each individual project on the environment [5]. Other construction firms became actively targeted by regulators requested to manage their performance according to the goals of sustainable development [6]. Zhao et al. [7] argue that the company which is considered socially responsible can benefit both by its enhanced reputation with the public, as well as its reputation within the business community, and at the same time increase its ability to attract capital and trading partners. Thus the incentives range from financial benefits to improved reputation in the community.

Secondly, rising public opposition can cause delays in the project realisation. This increases project costs and as the result lowers its financial performance. Infrastructure projects are rightfully referred as essential ingredients for productivity, output, or long-term growth of the modern economies [8]. At the micro level infrastructure usually, yields a significant social benefit and substantially improves the quality of life [9]. Nevertheless, each project still can encounter a resistance from local communities which impose the financial risk on investment by potentially delaying project implementation, increasing the cost of implementation, and undermining project viability [10] [11]. Why is this case? Generally, there always are stakeholders-groups of people whose lives or environment are affected by the project, but who receive no direct benefit from it [12]. Neglecting stakeholders' concerns can impose a substantial risk on the viability of the project. For example Keystone XL pipeline in North America, the Belo Monte Dam in Brazil, and the Bujagali Dam in Uganda undergone substantial 
changes and incurred a financial loss due to public opposition [13]. In Europe, for example, motorway link Rijksweg A4 in the Netherlands, Eurotunnel between France and the UK also faced public opposition causing substantial project delays [3]. Noteworthy that in developed economies public opposition concerns focuses mainly on adverse health effects and environment protection, while in developing countries the focus is mainly on the land take, relocation and livelihoods impact [3].

Thirdly, not complying with environmental and social performance standards set by Equator Principles Financial Institution may result in the withholding of funds or even blacklisting. For example one of the corporate investors (ING) stopped financing the construction of the Orion paper pulp mill project in Uruguay through the Equator Principles [14]. Equator Principles framework comprises a set of environmental and social guidelines that regulate finance transactions in global projects. Currently, there are more than 80 banks (holding about three-quarters of the project finance capital) who have adopted Equator Principles [15]. There still is an open question on whether the banks have implemented the principles properly as compliance by these banks is rather mixed [16] [17] [18].

While there seem to be a degree of coherence in regards to ESR related transmission channels, the overall conclusion on the effect of specific ESR factors is not a clear cut. Thus in twenty academic studies ten suggested a positive relationship between ESR factors and portfolio performance [19]-[28] with seven reporting a neutral effect [29]-[35] and three reporting a negative relationship [36] [37] [38]. A numerous research points out the need to properly incorporate environmental and social risk management strategy in order to achieve a higher sustainable performance of the construction projects [39] [40] [41] [42] [43]. Failing to do so, most importantly during the project feasibility study, may have fatal consequences on the project financial performance [44]. Environmental and social laws will impose liabilities and constraints on a project, thus the cost of compliance can be significant [11]. On the other hand a company that is efficient in managing environmental and social issues might avoid unforeseen costs, violation of agreed delivery time terms and the budget. The study by Zhao et al. [7] also reveals a direct link between ESR issues and performance of the construction project.

Also at issuer level, the environmental and social performance is seen to have a long-term impact on corporate finance [45] [46]. The study by Bauer [47] explores 585 US corporate bonds issued during 1996 and 2005. It concludes that companies with poor environmental management incurred a higher cost of debt, lower bond and issuer ratings. This conclusion is consistent with research outcomes of Chava [48] and Schneider [49]. Studying corporate bonds, Bauer et al. [50] and Kane et al. [51] both suggested that stronger employee relations have a positive effect on the financial performance of a company and its capability to sustain finical distress. The research conducted by Swaffield and Johnson [52] 
established that there are direct and indirect financial benefits gained as a consequence of Implementing ISO 14,000 series (mainly related to environmental issues) at contraction sites.

One of the key problems that industry faces is the difficulty of obtaining the uniform data on ESR that can be measured. As the result, the balance sheets and income statements do not explicitly reflect these potential risks.

Our hypothesis regards the link between ESR concerns and risk-return profile of infrastructure bonds. We argue that the issuers with poor environmental practices are more likely to deteriorate the value of infrastructure bonds (for example due to a higher exposure to potentially costly environmental litigation, reputational losses, and regulatory risk) which results in a higher finical risk for the bond investors. Thereby the current study attempts to identify the ESR factors that impose the financial risk on the infrastructure project investor. To this end, the econometric analysis was conducted on the sample of global infrastructure bonds. The aspects of this analysis involve the use of additive regression models (with four-parameter flexible distribution) for modelling non-linear effects between the response variable (which accounts for the risk-return profile of a bond) and covariates (accounting for the bond and issuer specific characteristics, ESR related data, etc.).

The paper is organised as follows. Section 2 introduces the conceptual modelling framework adopted in the current study. Section 3 overviews the data set, describes data cleaning process and defines the variables. Section 4 introduces the model selection methodology and its modification developed to overcome certain data sample limitations of the current study. Section 5 presents modelling results. Section 6 discusses out-of-sample model validation and Section 7 concludes the paper.

\section{Modelling Framework}

In order to estimate the relationship between financial risk and ESR factors this study utilises a class of models known as General Adaptive Models of Location, Shape, and Scale (GAMLSS) [53] primarily for two main reasons.

First of all in GAMLSS the distribution of the response variable is not limited to exponential family (e.g. Normal distribution), instead, more general (e.g. highly skewed and/or kurtotic) distributions are allowed. This is particularity important in the context of non-normally distributed response variable used in this study. Moreover, GAMLSS capability for modelling up to four distribution parameters (which are usually associated with location, dispersion, skewness and kurtosis of distribution) can provide the estimates not only for the expectation itself but also for the balance of risk around it. In particular, this modelling framework is very efficient in detecting the presence of tail events, asymmetry of risks and non-linearity of effects.

Secondly, in GAMLSS all distribution parameters can be modelled as linear, non-linear, parametric and nonparametric additive functions of covariates. The 
utilisation of nonparametric additive functions is particularly important when the studied relationships are not known in advance (as for example in our study). Thus the GAMLSS framework allows for estimating a functional form of the non-linear relationship for each distribution parameter from the data without a need for prior specification of the exact mathematical form.

The generalised additive model for location, scale and shape can be expressed as follows:

$$
\begin{aligned}
& \boldsymbol{Y} \sim \mathcal{D}(\boldsymbol{\mu}, \boldsymbol{\sigma}, \boldsymbol{v}, \boldsymbol{\tau}) \\
& g_{1}(\boldsymbol{\mu})=\boldsymbol{X}_{1} \boldsymbol{\beta}_{1}+s_{11}\left(\boldsymbol{x}_{11}\right)+\cdots+s_{1 J_{1}}\left(\boldsymbol{x}_{1 J_{1}}\right) \\
& g_{2}(\boldsymbol{\sigma})=\boldsymbol{X}_{2} \boldsymbol{\beta}_{2}+s_{21}\left(\boldsymbol{x}_{21}\right)+\cdots+s_{2 J_{2}}\left(\boldsymbol{x}_{2 J_{2}}\right) \\
& g_{3}(\boldsymbol{v})=\boldsymbol{X}_{3} \boldsymbol{\beta}_{3}+s_{31}\left(\boldsymbol{x}_{31}\right)+\cdots+s_{3 J_{3}}\left(\boldsymbol{x}_{3 J_{3}}\right) \\
& g_{4}(\tau)=\boldsymbol{X}_{4} \boldsymbol{\beta}_{4}+s_{41}\left(\boldsymbol{x}_{41}\right)+\cdots+s_{4 J_{4}}\left(\boldsymbol{x}_{4 J_{4}}\right)
\end{aligned}
$$

where $\boldsymbol{Y}$ denotes the vector of response variable elements distributed with probability density function $\mathcal{D}$ which is conditional on the vector of distribution parameters $\boldsymbol{\theta}=(\boldsymbol{\mu}, \boldsymbol{\sigma}, \boldsymbol{\nu}, \boldsymbol{\tau}) ; \boldsymbol{X}_{k}$ are the matrices of the covariates and $\boldsymbol{\beta}_{k}$ are the regression parameters to be estimated, $s_{k j}$ are the smooth functions of covariates $\boldsymbol{x}_{k j}$ for $k=1,2,3,4$ and $j=1,2, \cdots, J_{k}$ while $g_{k}$ are known monotonic link functions. Thus $\boldsymbol{X}_{k} \boldsymbol{\beta}_{k}$ denote parametric terms while $\sum_{j=1}^{J_{k}} s_{k j}\left(\boldsymbol{x}_{k j}\right)$ denote non-parametric terms (e.g. spline functions). Note the matrices $\mathbf{X}_{k}$ and covariates $\quad \boldsymbol{x}_{k j}$ may differ across distribution parameters.

The spline functions in this study are modelled using thin plate regression splines [54]. Thin plate splines constitute a method for selecting the degree of smoothing for spline function based on generalised Akaike information criteria (GAIC) [55]. Important to note that non-linear relationships (the case when the degree of spline function is above 1) can be reduced to linear relationships by smoothing algorithm if this facilitates a better model's fit to the data.

\section{Data}

All the datasets used in the project are obtained from the Bloomberg database. Being a leading vendor of financial information, Bloomberg, from 2014 also provides an access to the environmental, social and governance (ESG) research assessments of a large number of the global companies. These ESG data cover the areas ranging from emissions and energy consumption to accident rates and governance structure. As all-in-one data terminal Bloomberg also provides functionality for linking bonds related information with ESG performance of selected companies. Thus, bonds were shortlisted as infrastructure related based on specification and content of "use of proceeds" document. This document discloses a detailed information for investors on how the invested funds will be used (usually provides a list of the projects to which bond proceeds will be allocated). The selected sample comprises bonds issued by both public and private issuers to finance 1) utilities, including power generation companies, electric and natural gas transmis- 
sion and distribution networks, long-haul energy pipelines, water and wastewater companies, and integrated utilities; 2) transport systems, including roads, bridges, ports, airports and rail networks; 3 ) other fundamental facilities serving a country, city or other particular area, such as stadiums, military installations and hospitals.

This study adopts the Z-spread as a measure of the risk-return profile of infrastructure bonds. Z-spread can be defined as a continuously compounded static spread over the London Interbank Offered Rate (LIBOR) curve (if the bond is held to maturity) such that the discounted cash flows of the bond are equal to its current market price. In other words, Z-spread quantifies what the market thinks of the bond value [56], thus making it a good measure for assessing the risk-return profile of different bonds.

Our study incorporates four sets of covariates (see Table 1), which account for 1) environmental and social risk; 2) macroeconomic conditions; 3) bond specific characteristics; and 4) issuer specific characteristics. We define environmental risk as the thread on living organisms and environment caused by emissions, wastes, resource depletion, etc. The social risk, besides environmental concerns (e.g., environmental degradation) can also be incurred by labour and human rights violations, corruption, marginalisation, social and economic stratification which disrupt or stop operations through strikes, sabotage, and violence. Social and environmental risks are well interconnected as one can emerge on the bedding of the other; therefore it is not usually possible to draw a clear line between the two. We select bond and issuer related covariates based on studies by Zmijewski [57], Altman [58]. In order to account for some common pitfalls and risks to holding infrastructure bonds, we introduce a set of macroeconomic variables to our analysis.

The collected data consists of a list of infrastructure bonds issued by various companies across the globe with trading periods unique for each bond. The trading periods span from issue date of each bond to 1 November 2016 or bond's maturity date (whichever is sooner). This results in unbalanced panel data that imposes certain modelling challenges in our study. To overcome that problem the data related to each bond was averaged over a number of years that bond was trading. Categorical binary variables (that alter by 0 or 1 ) were rounded to the nearest whole number after the averaging. All continuous environmental and social risk factors were divided by issuer's tangible assets to form ratios in order to account for the asymmetry of environmental and social impacts due to the scale of the business. Finally, all continuous variables were centred and scaled according to the following rule: $\frac{x_{i}-\bar{x}}{\sigma(x)}$, in order to facilitate the fitting of a probability distribution to a series of data.

As the result of non-reporting or lack of relevance for an industry group, there is a large amount of missing observations for the ESR-related and other covariates in the data. We anticipate that extrapolating the covariants beyond the 
Table 1. Covariates used in the analysis.

Covariate

\section{Environmental risk factors}

Environmental disclosure score-measure based on the extent of a company's environmental disclosure

Total energy consumption-includes energy consumed as electricity or through combustion in boilers, vehicles, etc.

Energy intensity per employee-energy consumed per employee

Total amount of electricity used

Total amount of water used

Water intensity per employee-water consumed per employee

Total $\mathrm{CO}_{2}$ emissions of the company

Number of employee representatives on the board

Environmental Cost-cost of environmental conservation and other environmental initiatives undertaken during the normal course of business

Environmental Quality Management-indicates whether the company has introduced any kind of environmental management system

Emission Reduction-indicates whether the company has implemented any initiatives to reduce its environmental emissions to air

Energy Efficiency Policy-indicates whether the company has implemented any initiatives to make its use of energy more efficient

Waste Reduction-indicates whether the company has implemented any initiatives to reduce its waste

Climate Change Policy—indicates whether the company has outlined its intention to help reduce global emissions of the Greenhouse Gases

Green Building-indicates whether the company has taken any steps towards using environmental technologies in construction of its buildings

\section{Social risk factors}

Research and development expenses divided by cash flow from operations

Personnel expenses per employee-personnel expenses divided by the number of employees

Number of employee representatives on the board

Social disclosure score-measure based on the extent of a company's social disclosure

Total number of company employees

Percentage of the board of directors that is comprised of non-executive directors

Number of directors on the company's board

Number of independent directors on the company's board

Percentage Independent Director-independent directors as a percentage of total board membership

Social Supply Chain-indicates whether the company has implemented any initiatives to reduce the social risks in its supply chain

Human Rights-indicates whether the company has implemented any initiatives to protect rights of all people it works with

ESG Linked Bonus-indicates whether executive compensation is linked to Environmental, Social and Governance goals

Health Safety Policy-indicates whether the company has recognized its health and safety risks 


\section{Continued}

Macroeconomic

Domestic base interest rate

Domestic inflation

Bond specific characteristics

Time to maturity of a bond, measured in years

Issuer specific characteristics

EBITDA—earnings before interest, taxes, depreciation and amortization

Total equity—firm's total assets minus its total liabilities

Ratio of net income to total assets

Ratio of total liabilities to total assets

Volatility 360 day-annualized standard deviation of the relative price change for the 360 most recent trading days

Return on capital-measures the return that an investment generates for capital contributors, in percentage

Price to book ratio-ratio of the stock price to the book value per share

Tangible assets-total assets minus intangible assets

Dividend Health Score-proxy for credit rating of the company, calculated based on company's fundamentals and ratings by rating agencies

Total Assets-total of all short and long-term assets as reported on the Balance Sheet.

Total liabilities—sum of all current and noncurrent liabilities

original observations (to replace missing values) will not be particularly meaningful given the context of the data used in our study. Instead, we attempt to address this issue by tailoring a suitable model selection methodology.

\section{Model Selection}

This study employs the model selection procedure (discussed in Stasinopoulos et al. [55]) in order to identify the model that is best supported by the data (referred to as parsimonious model). In particular, in GAMLSS the model selection is mainly concerned with selecting appropriate distribution for the response variable and the relevant covariates (e.g. risk factors) for distribution parameters. Moreover, it prevents overfitting, underfitting and addresses the causation problem to some degree. The model selection is performed based on the generalised Akaike information criteria (GAIC). That is the model with the smallest GAIC value is identified as the parsimonious model.

$$
\operatorname{GAIC}(k)=G D+(k \cdot d f)
$$

where $G D$ is a global deviance of the model, $d f$ is a number of effective degrees of freedom of the fitted model and $k$ is a specific penalty. For example $k=2$ and $k=\ln (n)$ (where $n$ is a sample size) correspond to Akaike information criterion [59] and Schwarz Bayesian criterion [60] accordingly. 
First, we selected a flexible four-parameter JSU distribution which is a reparameterization of the original Johnson's Su distribution [61]. Figure 1 illustrates the histogram of Z-spreads in the studied sample with fitted JSU and normal distribution probability functions. The vertical axis represents the frequency count, while the horizontal axis shows the range of scaled Z-spread values observed. A visual analysis suggests that the flexible JSU distribution fits the data better as, unlike normal distribution; it is able to capture skewness and excess kurtosis of the data. Moreover, despite its great flexibility, JSU distribution also offers excellent interpretability properties. Parameters $\mu$ and $\sigma$ exactly define the mean (location) and standard deviation (scale) of the distribution, while the shape parameters $v$ and $\tau$ are associated with skewness and kurtosis of the distribution. This flexibility is expected to provide us with the better estimates of the balance of risk around the mean.

Secondly, the step-wise selection of covariates (schematically illustrated in Figure 2) is done in two stages-forward and backwards procedures. In the forward procedure, the algorithm iterates through distribution parameters and checks in sequence each covariate for inclusion into the model. It stops when none of the remaining covariates can further improve the GAIC score. This consecutive process may render some of the earlier included covariates non-significant. Thus in order to ensure that the model incorporates only significant variables the forward procedure is followed by the backwards procedure. In the backwards procedure, the earlier included covariates are checked again successively for the significance in order to be kept in or removed from the model.

Finally, when the best model is selected with the step-wise procedure discussed above, we refit this model by constructing an extra null space penalty

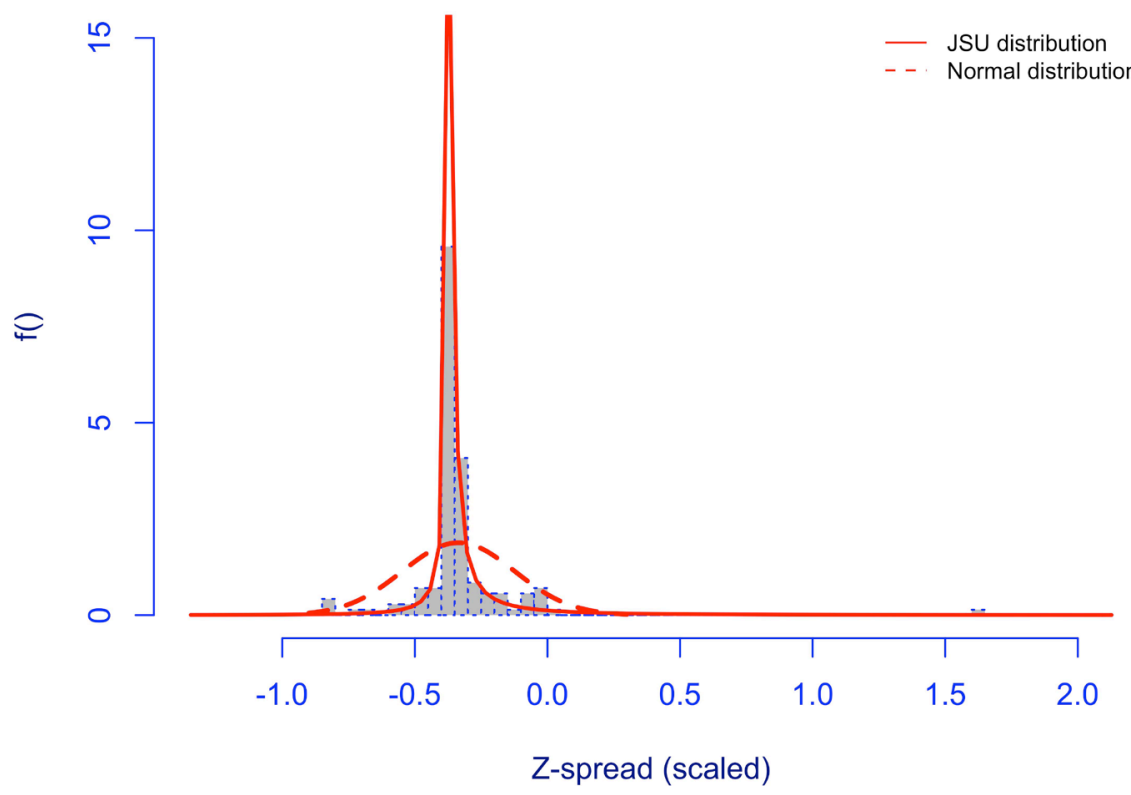

Figure 1. The Z-spread and the fitted JSU vs NO distribution. 


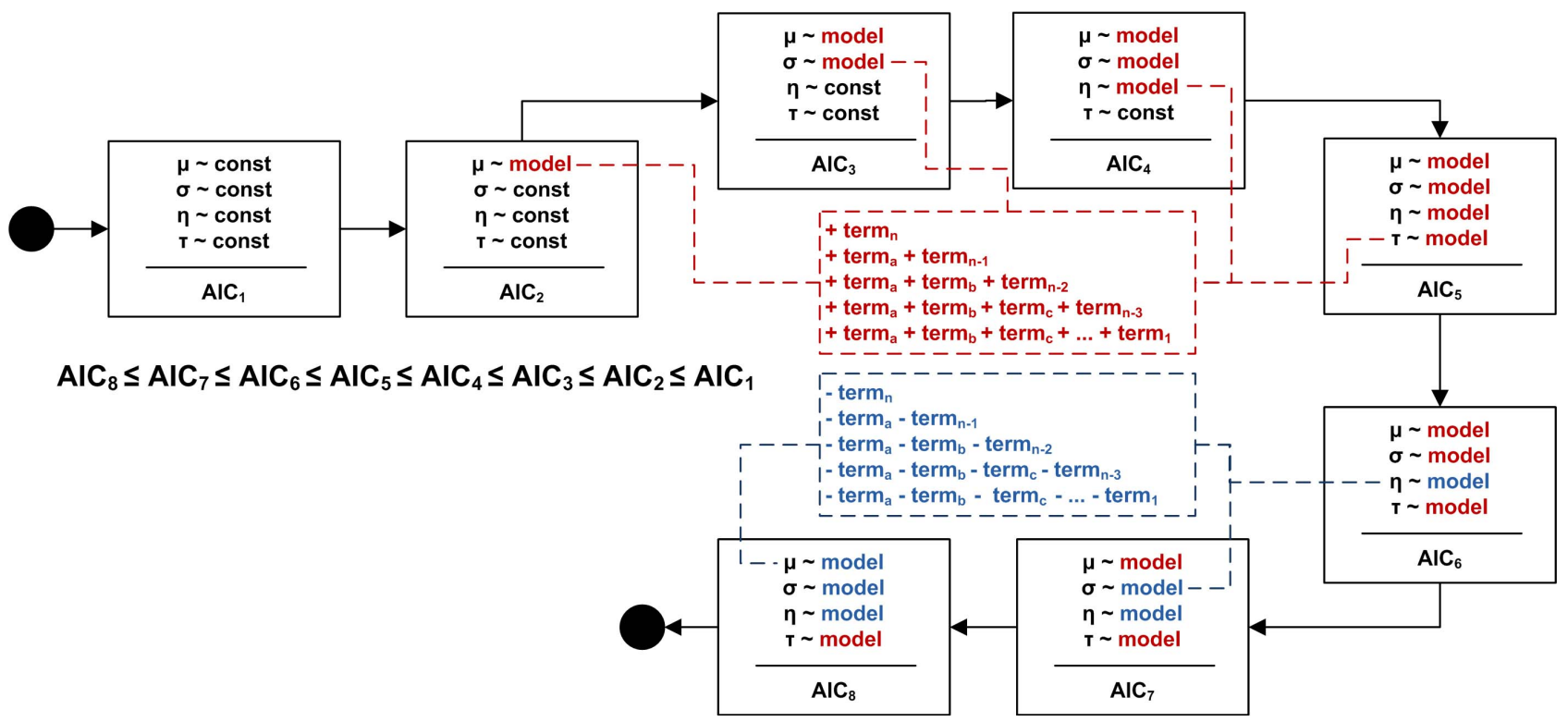

Figure 2. Flowchart of the model selection strategy.

for each smooth function. This is an additional measure that guarantees that effects of insignificant covariates are penalised to zero and dropped out from the model.

All covariates listed in the Table 1 were supplied to the model selection algorithm discussed above. The algorithm has converged to the following parsimonious model:

$$
\begin{aligned}
& \text { ZSPREAD JSU }(\boldsymbol{\mu}, \boldsymbol{\sigma}, \boldsymbol{v}, \boldsymbol{\tau}) \\
& \begin{aligned}
\boldsymbol{\mu}= & \alpha^{\mu}+f_{\mu 1}(T T M)+f_{\mu 2}(I N T)+f_{\mu 3}\left(C O_{2}\right)+f_{\mu 4}(C R H)+f_{\mu 5}(I D I R) \\
\quad & +f_{\mu 5}\left(C_{2}: I D I R\right)+f_{\mu 6}(I N T: C R H)+f_{\mu 7}(T T M: I D I R)
\end{aligned} \\
& \ln (\boldsymbol{\sigma})=\alpha^{\sigma}+f_{\sigma 1}(E N E)+f_{\sigma 2}(C R H)+f_{\sigma 3}(E N E: C R H) \\
& \boldsymbol{v}=\alpha^{v} \\
& \ln (\tau)=\alpha^{\tau}
\end{aligned}
$$

where ZSPREAD is Z-spread of an infrastructure bond; TTM is a time to maturity; INT is domestic base interest rate; $\mathrm{CO}_{2}$ amount of carbon dioxide emission to tangible assets ratio; $C R H$ is a dividend health of an issuer; IDIR is a percentage of independent directors engaged; ENE is energy consumption to tangible assets ratio; JSU is a reparameterization of the original Johnson's Su distribution; $f($.) is a smooth function of the covariates. Following a data-driven modelling approach in this study we do not assume any particular mathematical form of $f($.$) in advance, instead, the form of f($.$) is estimated from the data.$

The model diagnostic stage involves the use of worm plots [62] to justify an adequacy of the model. Worm plots are de-trended normal Q-Q plots of the quantile residuals ( $\mathrm{z}$-scores). Figure 3 contains the de-trended Q-Q plot for the JSU distribution of $z$-scores over the studied sample of bond Z-spreads. The normalised residuals (yellow dots on the Figure 3 ) are close to the origin and are located 


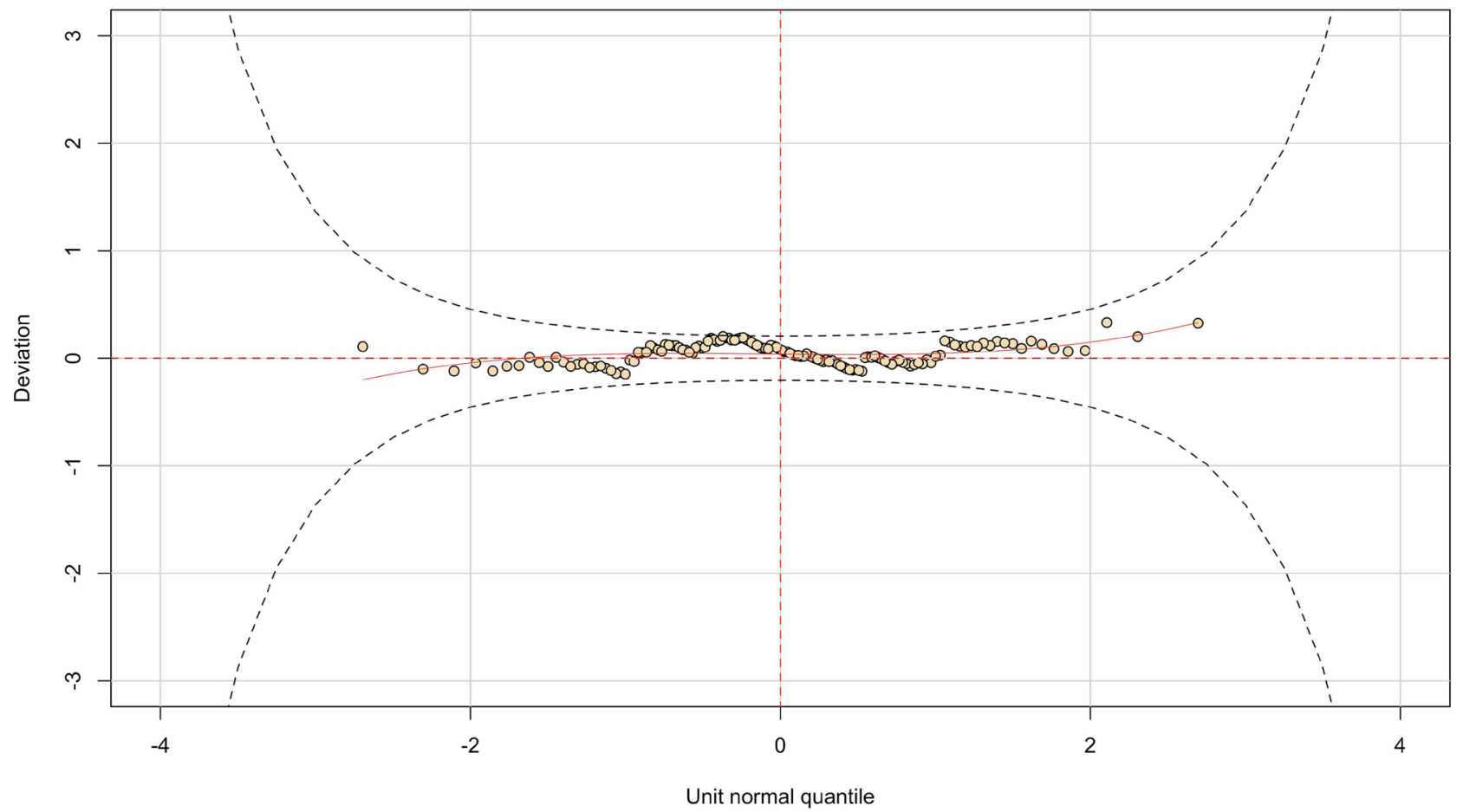

Figure 3. Worm plot of residuals of fitted bond default model.

between dashed lines ( 95 percent confidence interval), indicating that the model is relatively adequate i.e. differences between the empirical and theoretical distributions are due to random variation only.

Matching all non-missing values of the selected covariates produced a sample of 142 infrastructure bonds issued by various companies across the globe from a range of industry sectors shown in Figure 4.

\section{Modelling Results}

This section provides a detailed interpretation on how the expected Z-spread and the balance of risk around it are conditioned on the ESR factors and other covariates.

\section{Financial risk: $\boldsymbol{\mu}$}

The location parameter $(\mu)$ characterises the expected Z-spread for a given bond. It provides the anticipated $Z$-spread in the long run and serves as one of the key measures for risk quantification. The model for location parameter is:

$$
\begin{aligned}
\mu= & \alpha^{\mu}+f_{\mu 1}(T T M)+f_{\mu 2}(I N T)+f_{\mu 3}\left(C_{2}\right)+f_{\mu 4}(C R H)+f_{\mu 5}(I D I R) \\
& +f_{\mu 5}\left(C O_{2}: I D I R\right)+f_{\mu 6}(I N T: C R H)+f_{\mu 7}(T T M: I D I R)
\end{aligned}
$$

Thus the expected Z-spread is directly affected by the time to maturity of a bond, base interest rate, level of carbon dioxide emission to tangible assets ratio, dividend health of an issuer, a percentage of independent directors engaged and various interactions of these covariates. The effects can be disintegrated as follows: 

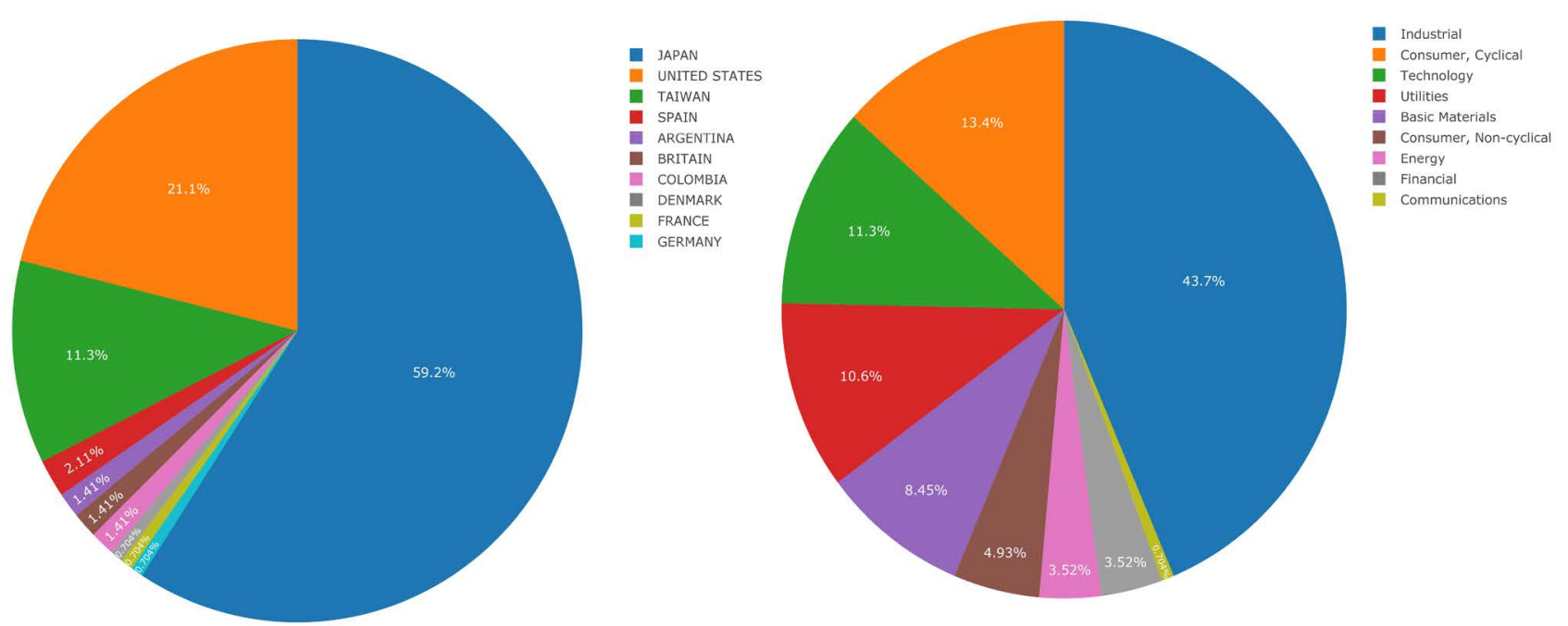

Figure 4. Distribution of infrastructure bonds by country and industry sector in the studied sample.

- TTM : Time to maturity has a positive linear effect on the expected Z-spread (see Figure 5 TTM plot) with the marginal effect equal to 0.018 . This overall fits the theory suggesting that spreads widen as maturities lengthen among the bonds (e.g. Beaumont [63]).

- INT : The base interest rate has a positive linear effect on the expected Z-spread (see Figure 5 INT plot) with the marginal effect equal to 0.034 . This kind of relationship between credit spreads and interest rate is associated with periods of an economic slowdown. Noteworthy that $76 \%$ of the infrastructure bonds in the studied sample were issued and actively traded after the year 2007, thus covering the finical crisis and subsequent recovery period.

- $\mathrm{CO}_{2}$ : The level of $\mathrm{CO}_{2}$ emission to tangible assets ratio has a positive linear effect on the expected Z-spread (see Figure $5 \mathrm{CO}_{2}$ plot) with the marginal effect equal to 0.006 . Thus we observe a higher expected $\mathrm{Z}$-spread for the issuers that have high $\mathrm{CO}_{2}$ to tangible assets ratio. The financial risk contribution from $\mathrm{CO}_{2}$ emission to tangible assets ratio in our sample is the highest on average for the companies from Energy, Utilities and Consumer Cyclical sectors which are indeed associated with higher (comparing to other sectors) $\mathrm{CO}_{2}$ output. Theretofore $\mathrm{CO}_{2}$ emission on top of being one of the key contributors to undesired environmental changes is also associated with higher financial risk in the area of infrastructure development.

- $C R H$ : The effect of issuer's dividend health on the expected Z-spread is an inverted U-shaped relationship (see Figure $5 \mathrm{CRH}$ plot) with the marginal effect equal to -0.002 . This dynamics is sensible and generally fits insights from multiple studies (e.g. Litterman and Iben [64], Bhojraj and Sengupta [65], etc).

- IDIR: The percentage of independent directors has a positive linear effect on the expected Z-spread (see Figure 5 IDIR plot) with the marginal effect equal to 0.007 . Independent directors are not employees of the firm, they neither 

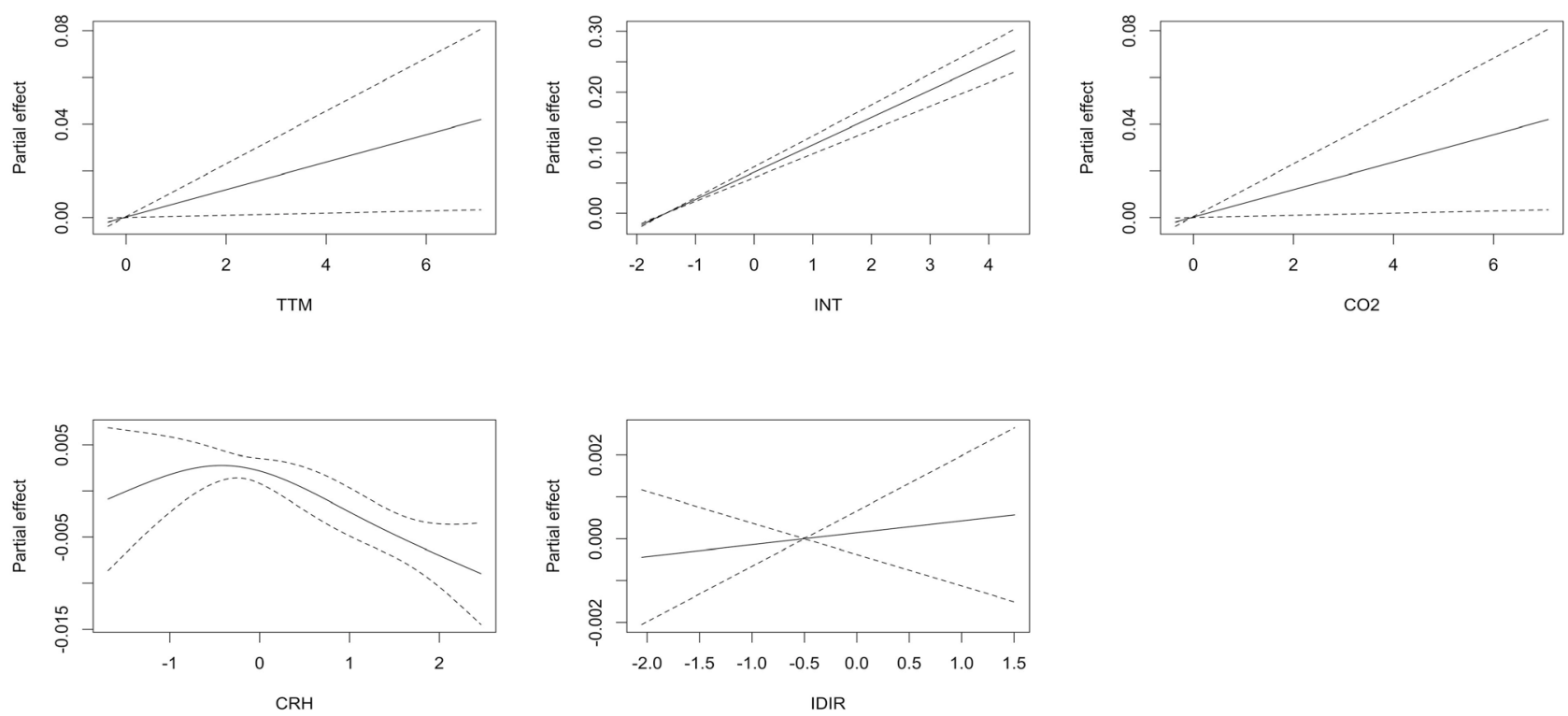

Figure 5. Partial effect of $\mu$ terms (TTM - time to maturity, INT - base interest rate, $\mathrm{CO}_{2}$-level of carbon dioxide emissions to tangible assets ratio, $C R H$-dividend health of an issuer, and IDIR - percentage of independent directors) on the expected Z-spread.

- own company's shares nor have any material relationship with the firm. Independent directors monitor the company to ensure that executives act also in the interest of shareholders. In general, the research evidence on the effectiveness of independent directors is not a clear cut, indicating both positive and negative aspects of this role in regards to firm's financial performance (e.g. Bhagat and Black [66], Knyazeva et al. [67], etc). Also, the percentage of serving independent directors varies greatly across various states. Thus the average percentage of independent directors is the highest for the US based companies (about 89\%) and lowest for Japanese companies (about 18\%). Perhaps a better approach would be estimating the partial effect of independent directors with the reference to a domestic country. However, this would require a considerably bigger data sample in order to obtain sensible results. Therefore this approach is suggested for the future research when more data become available.

- $\left(\mathrm{CO}_{2}: \mathrm{IDIR}\right)$ : The interaction surface (Figure $6 \mathrm{CO}_{2}$ : IDIR plot) illustrates a simultaneous effect of $\mathrm{CO}_{2}$ and IDIR on the expected Z-spread. Interesting to note here that as the percentage of independent directors increases the marginal effect of $\mathrm{CO}_{2}$ on the expected Z-spread declines. Note, that percentage of independent directors varies greatly across different countries; presumably the effect of $\mathrm{CO}_{2}$ emission could also have an un-uniform interstate distribution. Given the size of the data sample used in the current study, this statement cannot be reliably explored. Therefore, this analysis is suggested for the future research when more data become available.

- (INT:CRH) : The interaction surface (Figure 6 INT: CRH plot) illustrates a simultaneous effect of INT and CRH on the expected Z-spread. 


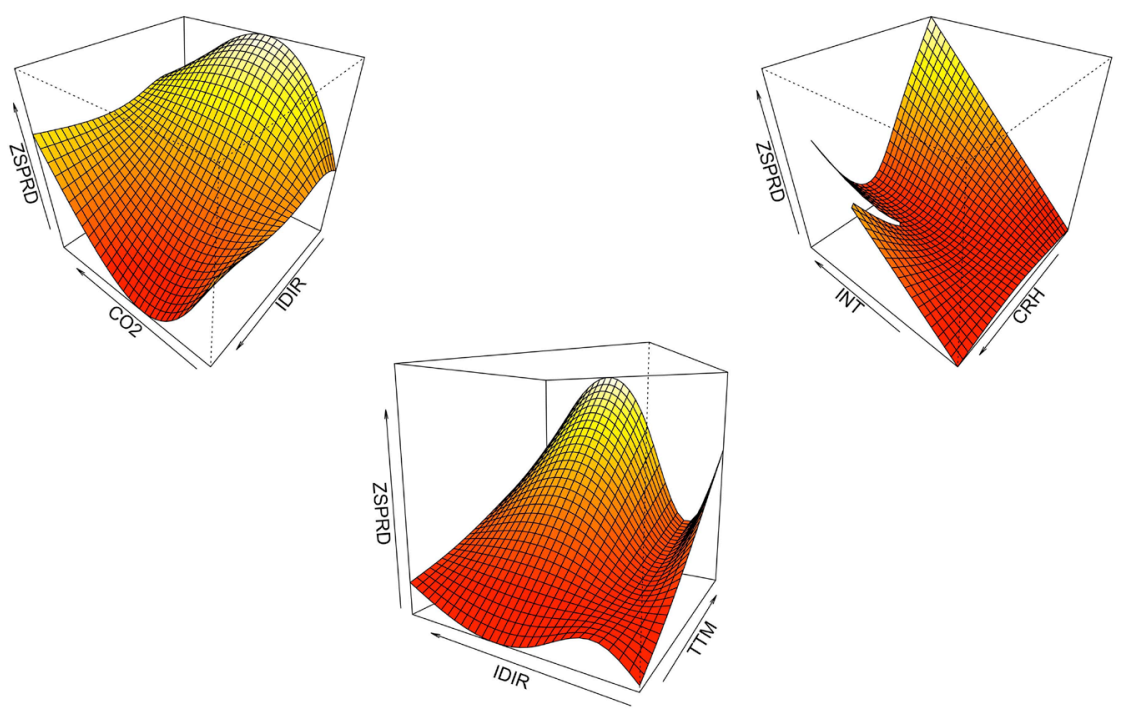

Figure 6. Interaction effects of $\mu$ terms (TTM - time to maturity, INT - base interest rate, $\mathrm{CO}_{2}$-level of carbon dioxide emissions to tangible assets ratio, $\mathrm{CRH}$-dividend health of an issuer, and IDIR - percentage of independent directors) on the expected Z-spread.

Noteworthy that the expected Z-spread is maximised when the base interest rate and dividend health of the issuer reach their higher and lower extremes accordingly. Overall we observe that in the economies with high interest rates the improvement in dividend health of the issuer has the strongest negative effect on the expected Z-spread of infrastructure bonds.

- (TTM:IDIR): The interaction surface (Figure 6 TTM: IDIR plot) illustrates a simultaneous effect of TTM and IDIR on the expected Z-spread. Noteworthy that TTM effect varies considerably depending on the percentage of independent directors engaged. Thus a higher percentage of independent directors can be associated with a stronger TTM impact on the expected Z-spread.

\section{Financial risk: $\sigma$}

The dispersion parameter $(\sigma)$ quantifies the degree to which the Z-spread fluctuates in relation to its expected value. It essentially characterises volatility (the tendency of the Z-spread to rise or fall substantially in a short period of time). A bond that is volatile is considered to have a higher risk because its performance may change quickly in either direction at any moment. The model for dispersion parameter $(\sigma)$ is:

$$
\ln (\sigma)=\alpha^{\sigma}+f_{\sigma 1}(E N E)+f_{\sigma 2}(C R H)+f_{\sigma 3}(E N E: C R H)
$$

Thus the Z-spread volatility is directly affected by the energy intensity per tangible assets ratio, dividend health of an issuer and interaction of these covariates. The effects can be disintegrated as follows:

- $C R H$ : The dividend health of an issuer has a negative linear effect on the Z-spread volatility (see Figure $7 C R H$ plot) with the marginal effect equal 

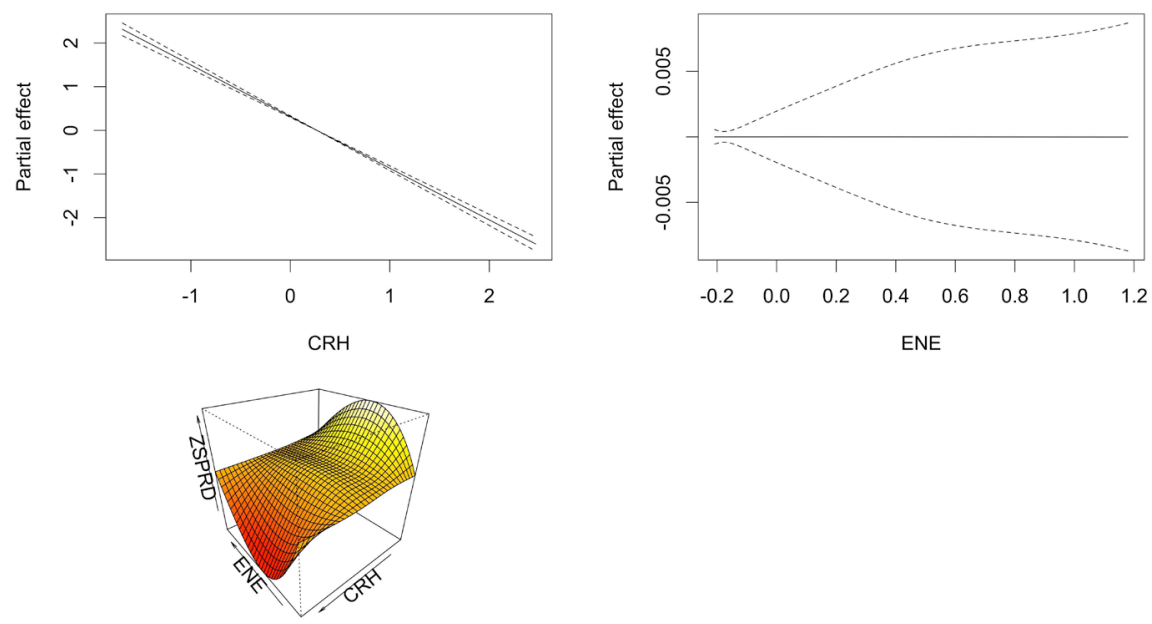

Figure 7. Partial and interaction effects of $\sigma$ terms ( ENE - energy intensity per tangible assets ratio and $C R H$-dividend health of an issuer) on the Z-spread volatility.

to -0.085 . This suggests that high dividend health, hence credit standing of the issuer lowers uncertainty around the expected Z-spread of the infrastructure bond.

- ENE : The energy intensity per tangible assets ratio has the average main effect on the Z-spread volatility equal to zero (see Figure 7 ENE plot). However the interaction surface spanned by $E N E$ and $C R H$ is not flat (see Figure $7 E N E: C R H$ plot). We observe an inverted u-shaped relationship between $E N E$ and Z-spread volatility for the bond issuer with low dividend health score, on the other hand, the effect between ENE and Z-spread volatility is a u-shaped relationship for the bond issuers with high dividend health score.

\section{Financial risk: $v, \tau$}

The remaining two parameters, namely $v$ and $\tau$ control skewness and kurtosis of the Z-spread distortion. In the model selection process none of the covariates when added to $v$ and $\tau$ could further improve the likelihood of making the data. As the result models for $v$ and $\tau$ are not conditioned on any of the studied covariates and represent intercept-only models. Nevertheless, the estimates for skewness and kurtosis are still useful as indicators highlighting deviation from normality for Z-spread distortion. Thus estimated $v$ parameter equal to -0.13 indicates a negative skewness of the Z-spread distortion (mass of the Z-spread distribution is concentrated on the right) suggesting a larger chance of observing high Z-spreads comparing to what the normal distribution would suggest. The estimated $\tau$ parameter equal to 0.43 indicates a considerable leptokurtic shape of the Z-spread distortion with heavy tails (higher probabilities for observing extreme tail Z-spreads than the normal distribution would suggest). Overall there is a substantial amount of skewness and kurtosis in the data that cannot be explained by the selection of covariates, however, these deviations from normality are well captured by the flexible JSU distribution. 
Table 2 summarises the effect types and average partial slopes between selected risk factors, expected absolute risk and uncertainty around it. Overall these results show that infrastructure bonds issued by firms with environmental and social risk concerns tend to have higher expected Z-spreads and wider uncertainty around the expectation. Moreover, asymmetric shape of the conditional Z-spread distribution and heavier tails (compared with the normal density function that is usually employed by conventional models) indicate a higher probability of exposure to a large financial risk.

\section{Out-of-Sample Model Validation}

In order to test the model's out-of-sample performance we used a quantile-based sampling algorithm to partition the initial dataset into separate training (80\% of original sample) and testing datasets ( $20 \%$ of original sample). The test was repeated 10 times and validation results were averaged (training and testing datasets each time were selected randomly). Each test is based on validation algorithm that minimises the global deviance for the training data set and then uses the validation set to calculate the prediction global deviance. This then was used to calculate a prediction error by dividing prediction global deviance over the number of observations in the validation data set.

The average prediction error equals -2.93 (0.88 - standard deviation), while the training error equals -4.45 with ( 0.25 - standard deviation). Lack of large discrepancies between training and testing prediction errors suggests that the selected model overall has a good out-of-sample performance. This result is benchmarked against a simple linear regression model that assumes a normally distributed response:

$$
\begin{aligned}
& \text { ZSPREAD NO }(\boldsymbol{\mu}, \boldsymbol{\sigma}) \\
& \begin{aligned}
\mu= & \alpha^{\mu}+T T M+I N T+C \mathrm{O}_{2}+C R H+I D I R \\
& +\mathrm{CO}_{2}: I D I R+I N T: C R H+T T M: I D I R
\end{aligned}
\end{aligned}
$$

Table 2. Regression summary.

\begin{tabular}{cccc}
\hline Distribution parameter & Predictor & Effect & Partial slope \\
\hline $8^{*} \mu$ (mean) & $T T M$ & linear positive & 0.018 \\
$I N T$ & linear positive & 0.034 \\
$C O_{2}$ & linear positive & 0.006 \\
$C R H$ & inverted u-shaped & -0.002 \\
& $I D I R$ & linear positive & 0.007 \\
& $C O_{2}: I D I R$ & non-linear interaction surface & - \\
& INT:CRH & non-linear interaction surface & - \\
& RRM:IDIR & non-linear interaction surface & - \\
& $C R H$ & linear negative & -0.085 \\
& ENE: $C R H$ & non-linear interaction surface & - \\
\hline
\end{tabular}


Note that the benchmark model has a considerably higher out-of-sample prediction error, equal 2.28 (5.43 - standard deviation). This highlights the advantage of data-driven non-parametric techniques and use of flexible distributions.

\section{Conclusions}

This study provides a comprehensive evidence that the issuer related ESR factors have financial risk implications for the infrastructure bond investors. Despite growing attention to environmental and social risk concerns in many industries, there are very few academic outputs (e.g. Lucas and Noordewier [68], Chen et al. [69]) that our conclusions can be generalised to. The results of this work extend previous research by identifying the exact ESR related factors (and the type of the relationships) which are associated with the expected finical performance and the balance of risk around the expectation of the global infrastructure projects.

The model developed in this study can provide guidance to policy-makers who might seek to foster or incentivize $\mathrm{CO}_{2}$ emission reduction by firms through the formulation of supporting policies (e.g., tax benefits, subsidies, etc.). Thus, the model can be used in estimating potential financial benefits achieved as the result of the implementation of such policies by firms. Similarly, the model could also provide comparative advantage to financial professionals by better estimating the risk-return probability distribution of infrastructure bonds.

Finally, a few limitations have to be discussed so that they can be addressed in the future research. First of all the type of paradigm employed in this study is a good choice for detecting complex relationships in the data, however, it is not always able to answer the question on why these relationships exist. Secondly, given the narrow specificity of the research question and difficulties in collecting ESR-related information, the studied sample comprises only a small portion of infrastructure bond issuers that disclose their public and social risk related information. This issue could be addressed potentially in the future research when more data are disclosed. To expand upon this research the future study should concentrate on improving the viability of developed model by benchmarking its results against industry insights and alternative modelling methodologies.

\section{References}

[1] ENDS (1992) Environmental Data Service Report. In: Survey Puts Landfill Clean-Up Costs in Perspective, Number 214, 11.

[2] Coulson, A.B. and Dixon, R. (1995) Environmental Risk and Management Strategy: The Implications for Financial Institutions. International Journal of Bank Marketing, 13, 22-29. https://doi.org/10.1108/02652329510078668

[3] Mark, H., Jaideep Das, S.M. and Martin, A. (2015) Effective Management of ESG Risks in Major Infrastructure Projects. Chapter 6, 47-55.

[4] Moneva, J.M., Rivera-Lirio, J.M., and Munoz-Torres, M.J. (2007) The Corporate Stakeholder Commitment and Social and Financial Performance. Industrial Management \& Data Systems, 107, 84-102. https://doi.org/10.1108/02635570710719070

[5] Ranjan, S.P. and Ruby, M.P. (2007) Improving the Occupational Health and Safety 
Measures in the Australian Construction Industry. Zagreb International Review of Economics and Business, 10, 17-34.

[6] Teo, M. and Loosemore, M. (2003) Changing the Environmental Culture of the Construction Industry. Chapter 50, 1-8. https://doi.org/10.1061/40671(2003)51

[7] Zhao, Z.-Y., Zhao, X.-J., Davidson, K. and Zuo, J. (2012) A Corporate Social Responsibility Indicator System for Construction Enterprises. Journal of Cleaner Production, 29-30, 277-289.

[8] Gramlich, E. (1994) Infrastructure Investment: A Review Essay. Journal of Economic Literature, 32, 1176-1196.

[9] Stewart, J. (2010) Public and Private Financing of Infrastructure. In: The UK National Infrastructure Plan 2010, European Investment Bank Papers, 28-34.

[10] Dani, A., Kessler, T. and Sclar, E. (2007) Making Connections: Putting Social Policy at the Heart of Infrastructure Development. New Frontiers of Social Policy. World Bank Publications.

[11] Delmon, J. (2011) Public-Private Partnership Projects in Infrastructure: An Essential Guide for Policy Makers. Cambridge University Press.

[12] Turner, J. (2008) The Handbook of Project-Based Management: Leading Strategic Change in Organizations. McGraw-Hill Education.

[13] Naderpajouh, N., Mahdavi, A., Hastak, M. and Aldrich, D.P. (2014) Modeling Social Opposition to Infrastructure Development. Journal of Construction Engineering and Management, 140, Article ID: 04014029. https://doi.org/10.1061/(ASCE)CO.1943-7862.0000876

[14] Lee, V. (2008) Enforcing the Equator Principles: An Ngo's Principled Effort to Stop the Financing of a Paper Pulp Mill in Uruguay. Northwestern Journal of International Human Rights, 6, 354-373.

[15] EP (2013) The Equator Principles. The Equator Principles, Geneva, 1-21.

[16] Scholtens, B. and Dam, L. (2007) Banking on the Equator. Are Banks That Adopted the Equator Principles Different from Non-Adopters? World Development, 35, 1307-1328. https://doi.org/10.1016/j.worlddev.2006.10.013

[17] Miles, K. (2013) The Origins of International Investment Law: Empire, Environment and the Safeguarding of Capital. Cambridge Studies in International and Comparative Law. Cambridge University Press. https://doi.org/10.1017/CBO9781139600279

[18] Watchman, P. (2005) Beyond the Equator. Environmental Finance, 6, 16-17.

[19] Cohen, M., Fenn, S., Naimon, J. and Service, I.R.R.C.E.I. (1995) Environmental and Financial Performance: Are They Related? Investor Responsibility Research Center, Environmental Information Service.

[20] Opler, T. and Sokobin, J. (1995) Does Coordinated Institutional Activism Work? An Analysis of the Activities of the Council of Institutional Investors. Working Paper (Charles A. Dice Center for Research in Financial Economics) Fisher College of Business, the Ohio State University.

[21] Smith, M.P. (1996) Shareholder Activism by Institutional Investors: Evidence from Calpers. The Journal of Finance, 51, 227-252. https://doi.org/10.1111/j.1540-6261.1996.tb05208.x

[22] Abramson, L. and Chung, D. (2000) Socially Responsible Investing: Viable for Value Investors? Journal of Investing, 9, 73-80. https://doi.org/10.3905/joi.2000.319381

[23] Statman, M. (2000) Socially Responsible Mutual Funds. Financial Analysts Journal, 
3, 30-39. https://doi.org/10.2469/faj.v56.n3.2358

[24] Gompers, P.A., Ishii, J.L. and Metrick, A. (2001) Corporate Governance and Equity Prices. Number 8449 in Working Paper Series, 1-67.

[25] Orlitzky, M., Schmidt, F.L. and Rynes, S.L. (2003) Corporate Social and Financial Performance: A Meta-Analysis. Organization Studies, 24, 403-441. https://doi.org/10.1177/0170840603024003910

[26] Derwall, J. (2004) The Eco-Effciency Premium Puzzle. ERIM Report Series Research in Management. Erasmus Research Institute of Management, Erasmus University.

[27] Vermeir, W. and Corten, F. (2005) Corporate Social Responsibility and Financial Performance. Corporate Governance: The International Journal of Business Insociety, 5, 129-138.

[28] Statman, M. (2006) Socially Responsible Indexes: Composition, Performance, and Tracking Error. The Journal of Portfolio Management, 3, 100-109. https://doi.org/10.3905/jpm.2006.628411

[29] Barnett, M.L. and Salomon, R.M. (2006) Beyond Dichotomy: The Curvilinear Relationship between Social Responsibility and Financial Performance. Strategic Management Journal, 27, 1101-1122. https://doi.org/10.1002/smj.557

[30] Bauer, R., Otten, R. and Rad, A.T. (2006) Ethical Investing in Australia: Is There a Financial Penalty? Pacific-Basin Finance Journal, 14, 33-48.

https://doi.org/10.1016/j.pacfin.2004.12.004

[31] Benson, K., Brailsford, T. and Humphrey, J. (2006) Do Socially Responsible Fund Managers Really Invest Differently? Journal of Business Ethics, 65, 337-357.

https://doi.org/10.1007/s10551-006-0003-8

[32] Brammer, S., Brooks, C. and Pavelin, S. (2006) Corporate Social Performance and Stock Returns: UK Evidence from Disaggregate Measures. Financial Management, 97-116. https://doi.org/10.1111/j.1755-053X.2006.tb00149.x

[33] Core, J.E., Guay, W.R. and Rusticus, T.O. (2006) Does Weak Governance Cause Weak Stock Returns? An Examination of Firm Operating Performance and Investors' Expectations. The Journal of Finance, 61, 655-687.

https://doi.org/10.1111/j.1540-6261.2006.00851.x

[34] Schröder, M. (2004) The Performance of Socially Responsible Investments: Investment Funds and Indices. Financial Markets and Portfolio Management, 18, 122-142. https://doi.org/10.1007/s11408-004-0202-1

[35] Bello, Z.Y. (2005) Socially Responsible Investing and Portfolio Diversification. Journal of Financial Research, 28, 41-57. https://doi.org/10.1111/j.1475-6803.2005.00113.x

[36] Chong, J., Her, M. and Phillips, G.M. (2006) To Sin or Not to Sin? Now That's the Question. Journal of Asset Management, 6, 406-417. https://doi.org/10.1057/palgrave.jam.2240191

[37] Geczy, C., Stambaugh, R.F. and Levin, D. (2005) Investing in Socially Responsible Mutual Funds. University of Pennsylvania, The Wharton School, 1-56.

[38] Hong, H. and Kacperczyk, M. (2009) The Price of Sin: The Effects of Social Norms on Markets. Journal of Financial Economics, 93, 15-36. https://doi.org/10.1016/j.jfineco.2008.09.001

[39] Shen, L.Y., Wu, Y.Z., Chan, E.H.W. and Hao, J.L. (2005) Application of System Dynamics for Assessment of Sustainable Performance of Construction Projects. Journal of Zhejiang University Science A, 6, 339-349.

https://doi.org/10.1631/jzus.2005.A0339 
[40] Ugwu, O. and Haupt, T. (2007) Key Performance Indicators and Assessment Methods for Infrastructure Sustainability-A South African Construction Industry Perspective. Building and Environment, 42, 665-680. https://doi.org/10.1016/j.buildenv.2005.10.018

[41] Fernandez-Sanchez, G. and Rodriguez-Lopez, F. (2010) A Methodology to Identify Sustainability Indicators in Construction Project Management-Application to Infrastructure Projects in Spain. Ecological Indicators, 10, 1193-1201. https://doi.org/10.1016/j.ecolind.2010.04.009

[42] Xue, X., Zhang, R., Zhang, X., Yang, R.J. and Li, H. (2015) Environmental and Social Challenges for Urban Subway Construction: An Empirical Study in China. International Journal of Project Management, 33, 576-588. https://doi.org/10.1016/j.ijproman.2014.09.003

[43] Shi, Q., Liu, Y., Zuo, J., Pan, N. and Ma, G. (2015) On the Management of Social Risks of Hydraulic Infrastructure Projects in China: A Case Study. International Journal of Project Management, 33, 483-496. https://doi.org/10.1016/j.ijproman.2014.06.003

[44] Shen, L., Tam, V.W., Tam, L. and bo Ji, Y. (2010) Project Feasibility Study: The Key to Successful Implementation of Sustainable and Socially Responsible Construction Management Practice. Journal of Cleaner Production, 18, 254-259. https://doi.org/10.1016/j.jclepro.2009.10.014

[45] Djuitaningsih, T. and Rahman, A. (2011) Pengaruh kecakapan manajerial terhadap kinerja keuangan perusahaan. Universitas Bakrie, 1, 158-175.

[46] Pirzada, K., Wickramasinghe, D., Moens, G.A., Hamid, A.F.A., Angelia, D. and Suryaningsih, R. (2015) The Effect of Environmental Performance and Corporate Social Responsibility Disclosure towards Financial Performance (Case Study to Manufacture, Infrastructure, and Service Companies That Listed at Indonesia Stock Exchange). Procedia-Social and Behavioral Sciences, 211, 348-355.

https://doi.org/10.1016/j.sbspro.2015.11.045

[47] Bauer, R. and Hann, D. (2010) Corporate Environmental Management and Credit Risk. Maastricht University, 1-44.

[48] Chava, S. (2014) Environmental Externalities and Cost of Capital. Management Science, 60, 2223-2247. https://doi.org/10.1287/mnsc.2013.1863

[49] Schneider, T.E. (2011) Is Environmental Performance a Determinant of Bond Pricing? Evidence from the Us Pulp and Paper and Chemical Industries. Contemporary Accounting Research, 28, 1537-1561. https://doi.org/10.1111/j.1911-3846.2010.01064.x

[50] Bauer, R., Derwall, J. and Hann, D. (2009) Employee Relations and Credit Risk. Social Science Research Network Working Paper Series, 1-43. https://doi.org/10.2139/ssrn.1483112

[51] Kane, G.D., Velury, U. and Ruf, B.M. (2005) Employee Relations and the Likelihood of Occurrence of Corporate Financial Distress. Journal of Business Finance and Accounting, 32, 1083-1105. https://doi.org/10.1111/j.0306-686X.2005.00623.x

[52] Swaffeld, L.M. and Johnson, G.A. (2005) The Financial Benefits of Implementing ISO 14001 within Construction Contracting Organizations. Architectural Engineering and Design Management, 1, 197-210.

[53] Rigby, R.A. and Stasinopoulos, D.M. (2005) Generalized Additive Models for Location, Scale and Shape. Journal of the Royal Statistical Society. Series C (Applied Statistics), 54, 507-554. https://doi.org/10.1111/j.1467-9876.2005.00510.x 
[54] Duchon, J. (1977) Splines Minimizing Rotation-Invariant Semi-Norms in Sobolev Spaces. In: Constructive Theory of Functions of Several Variables, Springer, Berlin, 85-100. https://doi.org/10.1007/BFb0086566

[55] Stasinopoulos, D., Rigby, R., Heller, G., Voudouris, V. and De Bastiani, F. (2017) Flexible Regression and Smoothing: Using GAMLSS in R. Chapman \& Hall/CRC.

[56] O’Kane, D. (2011) Modelling Single-Name and Multi-Name Credit Derivatives. The Wiley Finance Series. Wiley.

[57] Zmijewski, M.E. (1984) Methodological Issues Related to the Estimation of Financial Distress Prediction Models. Journal of Accounting Research, 59-82. https://doi.org/10.2307/2490859

[58] Altman, E.I. (1968) Financial Ratios, Discriminant Analysis and the Prediction of Corporate Bankruptcy. The Journal of Finance, 23, 589-609. https://doi.org/10.1111/j.1540-6261.1968.tb00843.x

[59] Akaike, H. (1974) A New Look at the Statistical Model Identification. IEEE Transactions on Automatic Control, 19, 716-723. https://doi.org/10.1109/TAC.1974.1100705

[60] Schwarz, G. (1978) Estimating the Dimension of a Model. The Annals of Statistics, 6, 461-464. https://doi.org/10.1214/aos/1176344136

[61] Johnson, N. (1954) Systems of Frequency Curves Derived from the First Law of Laplace. Trabajos de estadística, 3, 283-291.

[62] Buuren, S.V. and Fredriks, M. (2001) Worm Plot: A Simple Diagnostic Device for Modelling Growth Reference Curves. Statistics in Medicine, 20, 1259-1277. https://doi.org/10.1002/sim.746

[63] Beaumont, P. (2004) Financial Engineering Principles: A Unified Theory for Financial Product Analysis and Valuation. Wiley Finance. Wiley.

[64] Litterman, R. and Iben, T. (1991) Corporate Bond Valuation and the Term Structure of Credit Spreads. Journal of Portolio Management, 17, 52-64. https://doi.org/10.3905/jpm.1991.409331

[65] Bhojraj, S. and Sengupta, P. (2003) Effect of Corporate Governance on Bond Ratings and Yields: The Role of Institutional Investors and Outside Directors. The Journal of Business, 76, 455-475. https://doi.org/10.1086/344114

[66] Bhagat, S. and Black, B.S. (2002) The Non-Correlation between Board Independence and Long-Term Firm Performance. Journal of Corporation Law, 27, 231-273.

[67] Knyazeva, A., Knyazeva, D. and Masulis, R.W. (2013) The Supply of Corporate Directors and Board Independence. Review of Financial Studies, 26, 1561-1605. https://doi.org/10.1093/rfs/hht020

[68] Lucas, M.T. and Noordewier, T.G. (2016) Environmental Management Practices and Firm Financial Performance: The Moderating Effect of Industry Pollution-Related Factors. International Journal of Production Economics, 175, 24-34. https://doi.org/10.1016/j.ijpe.2016.02.003

[69] Chen, P.-H., Ong, C.-F. and Hsu, S.-C. (2016) Understanding the Relationships between Environmental Management Practices and Financial Performances of Multinational Construction Firms. Journal of Cleaner Production, 139, 750-760. https://doi.org/10.1016/j.jclepro.2016.08.109 